\title{
Mycoleptodonoides aitchisonii suppresses asthma via Th2 and Th1 cell regulation in an ovalbumin-induced asthma mouse model
}

\author{
SOON-YOUNG LEE ${ }^{1 *}$, CHUN-SIK BAE $^{2 *}$, JI-HYE SEO $^{1}$, SEUNG SIK CHO ${ }^{3}$, \\ MIN-SUK BAE ${ }^{4}$, DEUK-SIL $\mathrm{OH}^{5}$ and DAE-HUN PARK ${ }^{1}$
}

\author{
${ }^{1}$ College of Oriental Medicine, Dongshin University, Naju, Jeollanam-do $58245 ;{ }^{2}$ College of \\ Veterinary Medicine, Chonnam National University, Gwangju 61186; ${ }^{3}$ Department of Pharmacy, College of Pharmacy, \\ Mokpo National University; ${ }^{4}$ Department of Environmental Engineering, College of Engineering, Mokpo National \\ University, Muan, Jeollanam-do 58554; ${ }^{5}$ Jeollanam-do Wando Arboretum, Wando, Jeollanam-do 59105, Republic of Korea
}

Received March 2, 2016; Accepted February 7, 2017

DOI: $10.3892 / \mathrm{mmr} .2017 .7901$

\begin{abstract}
Asthma is a chronic respiratory disease related to hyper-responsiveness. The majority of patients suffer mild symptoms, however, some cases, especially in the young and the elderly, can lead to death by apnea. Mycoleptodonoides atichisonii (M. atichisonii) is an edible mushroom that has previously been reported to possess several bioactive properties, such as the synthesis of nerve growth factors, anti-obesity effects and the ability to prevent cell death. In the current study, the authors evaluated the anti-asthmatic effects of $M$. atichisonii using an ovalbumin-induced asthma mouse model. $M$. atichisonii dose-dependently suppressed the levels of white blood cells, eosinophils and immunoglobulin $(\mathrm{Ig}) \mathrm{E}$ in $\mathrm{BALB} / \mathrm{c}$ mice, resulting from ovalbumin-induced asthma. M. atichisonii recovered the typical asthmatic morphological changes in lungs, such as mucous hyper-secretion, epithelial layer hyperplasia, eosinophil infiltration and various cell surface molecules, such as CD3, CD4, CD8, CD19 and major histocompatibility complex class II. With the exception of CD19+ cells and IL-12p40, M. atichisonii affected almost all factors related to asthma induction including the T helper (Th)1/Th2 transcription factors, T-bet and GATA-3, Th1-related cytokines, Th2-related cytokines and proinflammatory cytokines. In addition, M. atichisonii significantly inhibited the expression of IL-5, IL-13 and IL-6. The authors concluded that $M$. atichisonii may be a promising drug candidate against asthma.
\end{abstract}

Correspondence to: Dr Deuk-Sil Oh, Jeollanam-do Wando Arboretum, Wando, Jeollanam-do 59105, Republic of Korea E-mail: ohye@korea.kr

Dr Dae-Hun Park, College of Oriental Medicine, Dongshin University, 185 Kyunjae-ro, Naju, Jeollanam-do 58245, Republic of Korea E-mail: dhj1221@naver.com

*Contributed equally

Key words: $M$. atichisonii, ovalbumin-induced asthma model, $\mathrm{T}$ helper 1 cell, $\mathrm{T}$ helper 2 cell

\section{Introduction}

Asthma is a severe respiratory disease classified as one of the hyper-responsive immune diseases. According to the 2013 report from the World Health Organization, asthma patients numbered 235 million worldwide in 2013 (1). The United States Environmental Protection Agency (EPA) estimated in 2013 that there were 25.9 million asthma patients in the USA alone. In addition, the EPA stated that asthma was among the most serious respiratory diseases that leads to hospitalization, especially in children under 15 years of age (2). Various allergens can trigger asthma, such as dust mites, cockroaches, pet dander, viral infections, pollen, mold, fungi, tobacco smoke and pollutants (1). Asthma is an incurable disease that is related to the pulmonary system, and presents itself with various symptoms ranging from coughing to constructive apnea, all resulting from mucous secretion, goblet cell hyperplasia, epithelial cell shedding, basement membrane thickening and eosinophil infiltration $(3,4)$.

Asthma may be induced by an imbalance of T helper (Th)1 and Th2 cells, as well as various other factors related to disease occurrence. The transcription factor, T-bet, serves a role as a Th1 cell transcription factor $(5,6)$, producing Th1-related cytokines including interferon (IFN) $-\gamma$, which is stimulated by T-bet to produce more T-bet in a positive feedback loop. Interleukin (IL)-12 is a key cytokine that regulates the balance between Th1 and Th2 cells (7). It consists of a p35 subunit expressed ubiquitously and a p40 subunit that is restricted to IL-12-producing cells (8). IL-12 stimulates Th1-related immunoglobulins, including $\operatorname{IgG} 2 \mathrm{a}$, and it influences Th cell trafficking (9).

GATA-3 is a Th2 cell transcription factor (10). In a manner similar to T-bet, GATA-3 regulates Th2-related cytokines and accelerates the differentiation of Th2-related cytokines, including IL-4. Following IL-4 differentiation by GATA-3, IL-4 stimulates the production of more GATA-3 in a positive feedback loop. IL-5 increases the eosinophil population (11). IL-13 and IL-4 enhance B cell activation and Ig E production (12). IL-6 is a proinflammatory cytokine (13) and, because it is a regulatory factor for CD4+ cell balance (14), IL-6 is an important factor in asthma regulation. TNF- $\alpha$ is 
a proinflammatory cytokine induced by mast cells that has several regulatory functions that are related to asthma, such as smooth muscle contraction (15), neutrophil and eosinophil attractions (16) and $\mathrm{T}$ cell activation, which involves cytokine release (17).

Symptomatic relievers have been investigated in the past as asthma is a hyper-responsive disease and is difficult to completely eradicate/cure (18). For several decades, steroids were commonly prescribed for asthma, but the drugs have many severe adverse effects such as inhibiting the growth of children $(19,20)$, cataracts and glaucoma, hypertension, hyperlipidemia, peptic ulcers, myopathy and immunological suppression (21). Consequently, there have been many efforts to find more effective candidates from natural products with fewer adverse effects $(22,23)$. M. atichisonii is a mushroom that has been consumed for a long time in East Asia (24) and has been reported to have several medicinal effects, such as the synthesis of nerve growth factors (25), anti-obesity (26) and the prevention of cell death (27).

In the present study, the authors attempted to identify anti-asthmatic drug candidates from natural products to reduce the adverse effects of existing therapies, and to develop a drug that is more effective against asthma. Using immunohistochemical studies, M. atichisonii was determined to reduce the physiological and histopathological changes related to asthma in the bronchoalveolar lavage fluid (BALF), including the number of white blood cells, differential cell count and immunoglobulin ( $\mathrm{Ig}) \mathrm{E}$ in the lungs, as well as the associated morphological changes and asthma-inducing factors.

\section{Materials and methods}

Mycoleptodonoides (M.) aitchisonii preparation. $M$. atichisonii used in the present study was provided by the Jeollanam-do Wando Arboretum (Wando, Korea). The fresh fruiting bodies were hot air-dried and ground into a powder. $M$. atichisonii extract was prepared by boiling $1 \mathrm{~kg}$ of mycelium powder in $10 \mathrm{l}$ filtered sterile water for $8 \mathrm{~h}$ at $50^{\circ} \mathrm{C}$. The supernatant was saved and the pellet was re-boiled with 10 1 water for $8 \mathrm{~h}$. Insoluble material was removed by filtration and a two-fold volume of cold ethanol was added to the filtrate to precipitate the polysaccharide. Following standing the mixture at $4^{\circ} \mathrm{C}$ overnight, the precipitate was collected by centrifugation $(4,000 \mathrm{x} \mathrm{g}, 30 \mathrm{~min}$ at room temperature). The precipitate was washed with ethanol and resuspended in water. The resuspended solution was then freeze-dried.

Ovalbumin-induced asthma mouse model. Six-week-old female BALB/c mice ( $n=80$; body weight, $22 \pm 2 \mathrm{~g}$ ) were purchased from Samtako Bio Co. (Osan, Korea), fed with an ad libitum diet and water, and housed in a controlled environment $\left(22 \pm 3^{\circ} \mathrm{C}, 12 \mathrm{~h}\right.$ light/dark cycle). They were then divided into six treatment groups: (i) Control, (ii) sterilized tap water with ovalbumin (OVA) induction, (iii) $1 \mathrm{mg} / \mathrm{kg} /$ day dexamethasone (DEX; Sam Nam Pharm, Chungcheongnam, Korea) with OVA induction, (iv) $10 \mathrm{mg} / \mathrm{kg} / \mathrm{day} M$. atichisonii with OVA induction, (v) $100 \mathrm{mg} / \mathrm{kg} / \mathrm{day}$ M. atichisonii with OVA induction and (vi) $1,000 \mathrm{mg} / \mathrm{kg} /$ day $M$. atichisonii with OVA induction. On days 1 and 8 , all mice were sensitized via intraperitoneal injection of $20 \mu \mathrm{g}$ OVA (cat no. A5503-50G;
Sigma-Aldrich; Merck KGaA, Darmstadt, Germany) and $1 \mathrm{mg}$ aluminum hydroxide hydrate (Prod \#77161; Thermo Fisher Scientific, Inc. Waltham, MA, USA) in $500 \mu 1$ saline. From days 21 to 25 , all mice, except for those used as control, were challenged once daily with 5\% OVA for 30 min using a nebulizer ( $3 \mathrm{ml} / \mathrm{min}$, NE-U17; Omron Corporation, Kyoto, Japan). During the same 5 day period, the treatment groups were also administered once daily with oral doses of sterilized tap water, DEX, 10,100 or $1,000 \mathrm{mg} / \mathrm{kg} /$ day $M$. atichisonii $1 \mathrm{~h}$ prior to the OVA challenge.

Ethics statement. All experiments were approved by the Institutional Animal Care and Use Committee at Dongshin University (Naju, Korea; approval no. 2014-08-04).

$B A L F$ analysis. A total of one day following the final treatment, the mice were anesthetized with intraperitoneal injections of $50 \mathrm{mg} / \mathrm{kg}$ Zoletil (Virbac, Carros, France), and their tracheas were cannulated with disposable animal feeding needles. Lavages were performed with three $0.4 \mathrm{ml}$ aliquots of cold phosphate-buffered saline (PBS; cat no. 17-516F; Lonza, Walkersville, MD, USA). BALF samples were collected and immediately centrifuged at $900 \mathrm{x}$ g for $5 \mathrm{~min}$ at room temperature (Sorvall Legend Micro 17R; Thermo Fisher Scientific, Inc.). The cell pellets were resuspended in PBS for total and differential cell counts. The numbers of total and differential cells were counted using the Hemavet Multispecies Hematology system ( $n=8$ per group; Drew Scientific Inc., Miami Lakes, FL, USA). Levels of IgE in the BALF were measured using a specific mouse IgE enzyme-linked immunosorbent assay kit (cat no. 555248; BD Biosciences, Franklin Lakes, NJ, USA), according to the manufacturer's protocol ( $n=8$ per group).

Histopathological analysis. Lung tissue was fixed in $10 \%$ (v/v) formaldehyde solution for 10 days at room temperature, dehydrated in a graded ethanol series (99.9, 90, 80 and 70\%), and embedded in paraffin. Paraffin-embedded lung tissue was then sectioned ( $4 \mu \mathrm{m})$ longitudinally and stained with hematoxylin and eosin. In addition, the sections were stained with Periodic Acid-Schiff (PAS; periodic acid; cat no. P7875; Sigma-Aldrich; Merck KGaA; Schiff's reagent; cat no HX54780633; EMD Millipore, Billerica, MA, USA) for the semi-quantitative analysis of glycoproteins.

Immunohistochemical analysis. Deparaffinized tissue sections were treated with $3 \%$ hydrogen peroxide in methanol for $10 \mathrm{~min}$ to remove endogenous peroxidase. Antigen retrieval was carried out with sodium citrate buffer $(0.1 \mathrm{M})$ using a microwave. The slides were incubated with normal serum to block non-specific binding and then incubated overnight at $4^{\circ} \mathrm{C}$ with the following primary antibodies (diluted 1:100 to 1:200): Rabbit anti-mouse CD3 polyclonal (cat no. ab5690; 1:100; Abcam, Cambridge, MA, USA), rat anti-mouse CD4 monoclonal (cat no. 14-9766; 1:200; eBioscience, Inc., San Diego, CA, USA), rat anti-mouse CD8 monoclonal (cat no. sc-18913; 1:100; Santa Cruz Biotechnology, Inc., Dallas, TX, USA), rabbit anti-mouse CD19 polyclonal (cat no. 250585; 1:100; Abbiotec, San Diego, CA, USA), rat anti-mouse MHC class II monoclonal (cat no. sc-59318; 1:100; Santa Cruz Biotechnology, Inc.), rabbit anti-mouse Tbx21/T-bet 
Table I. Operation parameters for the GC/MS.

\begin{tabular}{|c|c|c|c|}
\hline Conditions & \multicolumn{3}{|c|}{$\mathrm{GC} / \mathrm{MS}^{\mathrm{a}}$} \\
\hline Column & \multicolumn{3}{|c|}{ J\&W Scientific, DB-5 cross-linked 5\% phenyl methyl silicone } \\
\hline Carrier & \multicolumn{3}{|c|}{ Helium } \\
\hline Split/splitless & \multicolumn{3}{|c|}{ Split 10:1 } \\
\hline Injection volume & \multicolumn{3}{|c|}{$1 \mu 1$} \\
\hline Detector & \multicolumn{3}{|c|}{ MS } \\
\hline MS source & \multicolumn{3}{|c|}{$230^{\circ} \mathrm{C}$} \\
\hline MS quad & \multicolumn{3}{|c|}{$150^{\circ} \mathrm{C}$} \\
\hline Conditions & Rate $\left({ }^{\circ} \mathrm{C} / \mathrm{min}\right)$ & Value $\left({ }^{\circ} \mathrm{C}\right)$ & Hold time (min) \\
\hline \multicolumn{4}{|c|}{ Analytical temperature } \\
\hline Initial & - & 65 & - \\
\hline Step 1 & - & 65 & 10 \\
\hline Step 2 & 10 & 300 & 22 \\
\hline Total & \multicolumn{3}{|c|}{$55.5 \mathrm{~min}$} \\
\hline Electron ionization & \multicolumn{3}{|c|}{$70 \mathrm{ev}$} \\
\hline Mass range & \multicolumn{3}{|c|}{$50-550 \mathrm{amu}$} \\
\hline Scan method & \multicolumn{3}{|c|}{ Full scan } \\
\hline
\end{tabular}

${ }^{\mathrm{a} H P}$ Agilent GC:7890A MS:5975C. GC/MS, Gas chromatography/mass spectrometry.

polyclonal (cat no. bs-3599R; 1:100; BIOSS, Beijing, China), goat anti-mouse GATA-3 (cat no. TA305795; 1:100; OriGene Technologies, Inc., Rockville, MD, USA), rat anti-mouse IFN- $\gamma$ monoclonal (cat no. sc-74104; 1:100), goat anti-mouse IL-12p35 polyclonal (cat no. sc-9350; 1:100), rat anti-mouse IL-12p40 monoclonal (cat no. sc-57258; 1:100) (all from Santa Cruz Biotechnology, Inc.), rabbit anti-mouse TNF- $\alpha$ polyclonal (cat no. 3053R-100; 1:200; BioVision Milpitas, CA, USA), rat anti-mouse IL-4 monoclonal (cat no. sc-73318; 1:100), rabbit anti-mouse IL-5 polyclonal (cat no. sc-7887; 1:100), goat anti-mouse IL-6 polyclonal (cat no. sc-1265; 1:100), and goat anti-mouse IL-13 polyclonal (cat no. sc-1776; 1:100) (all from Santa Cruz Biotechnology, Inc.). The slides were incubated for $10 \mathrm{~min}$ with a biotinylated secondary antibody (cat no. PK-7800; Vector Laboratories, Inc., Burlingame, CA, USA) and horseradish-peroxidase conjugated streptavidin. Signals were detected using a 3,3-diaminobenzidine tetrahydrochloride substrate chromogen solution (cat no. SK-4105; Vector Laboratories), and cells were counterstained with Mayer's hematoxylin. To determine the number of positively stained cells, five random, non-overlapping fields of view were selected, and cells were counted (magnification, x200) from three separately immunostained lung sections per animal $(n=8$ per group).

Gas chromatography/mass spectrometry (GC-MS) analysis. GC-MS (Agilent 5975C MSD and 7890A GC; Agilent Technologies, Inc., Santa Clara, CA, USA) was tuned by perfluorotribuylamine (cat no. 442747; Sigma-Aldrich; Merck KGaA) using three mass fragments $(\mathrm{m} / \mathrm{z})$ of 69.0 , 219.0 and 502.0 in the condition of electron ionization. A 5MS GC column (DB-5 cross-linked 5\% phenylmethyl silicone; Agilent Technologies, Inc.) was used for the analysis as this column has low bleed that improves sensitivity for constituent identification. The GC oven was heated using the following program: Isothermal at $65^{\circ} \mathrm{C}$ for $10 \mathrm{~min}$ and increasing by $10^{\circ} \mathrm{C}$ every min to $300^{\circ} \mathrm{C}$ with $\mathrm{He}$ as the carrier gas. The summarized operation parameters for the GC-MS are presented in Table I. In order to analyze the quality of extract in M. aitchisonii, the certain amount of dried samples by dehydrofreezing procedure was prepared. The samples were extracted using $10 \mathrm{~min}$ sonication at room temperature, twice with dichloromethane, followed by sonication twice with acetone using a sonicator (Bransonic ${ }^{\circledR} \mathrm{CPXH}$; Branson Ultrasonics Corporation, Dallas, TX, USA). The composited extract was evaporated by high volume nitrogen blowdown (TurboVap II; Caliper Life Sciences, Hopkinton, MA, USA) to reach $5-10 \mathrm{ml}$ and was further evaporated to a final volume of $100 \mu \mathrm{l}$ using low volume nitrogen blowdown (MGS-2200; Tokyo Rikakikai Co., Ltd., Tokyo, Japan). A final extract volume of $100 \mu \mathrm{l}$ was sialylated with N,O-bis(trimethylsilyl) trifluoroacetamide (Supelco; Sigma-Aldrich; Merck KGaA) to derivatize the constituents to their trimethylsilyl-derivatives (TMS-derivatives) prior to GC-MS analysis.

Statistical analysis. Data are presented as the mean \pm standard deviation. Group differences were evaluated by one-way analysis of variance followed by Dunnett's multiple comparison tests. Statistical significance was set at $\mathrm{P}<0.05$ or $\mathrm{P}<0.01$.

\section{Results}

M. atichisonii dose-dependently suppressed the populations of WBCs and eosinophils in BALF. In the OVA-induced asthma 


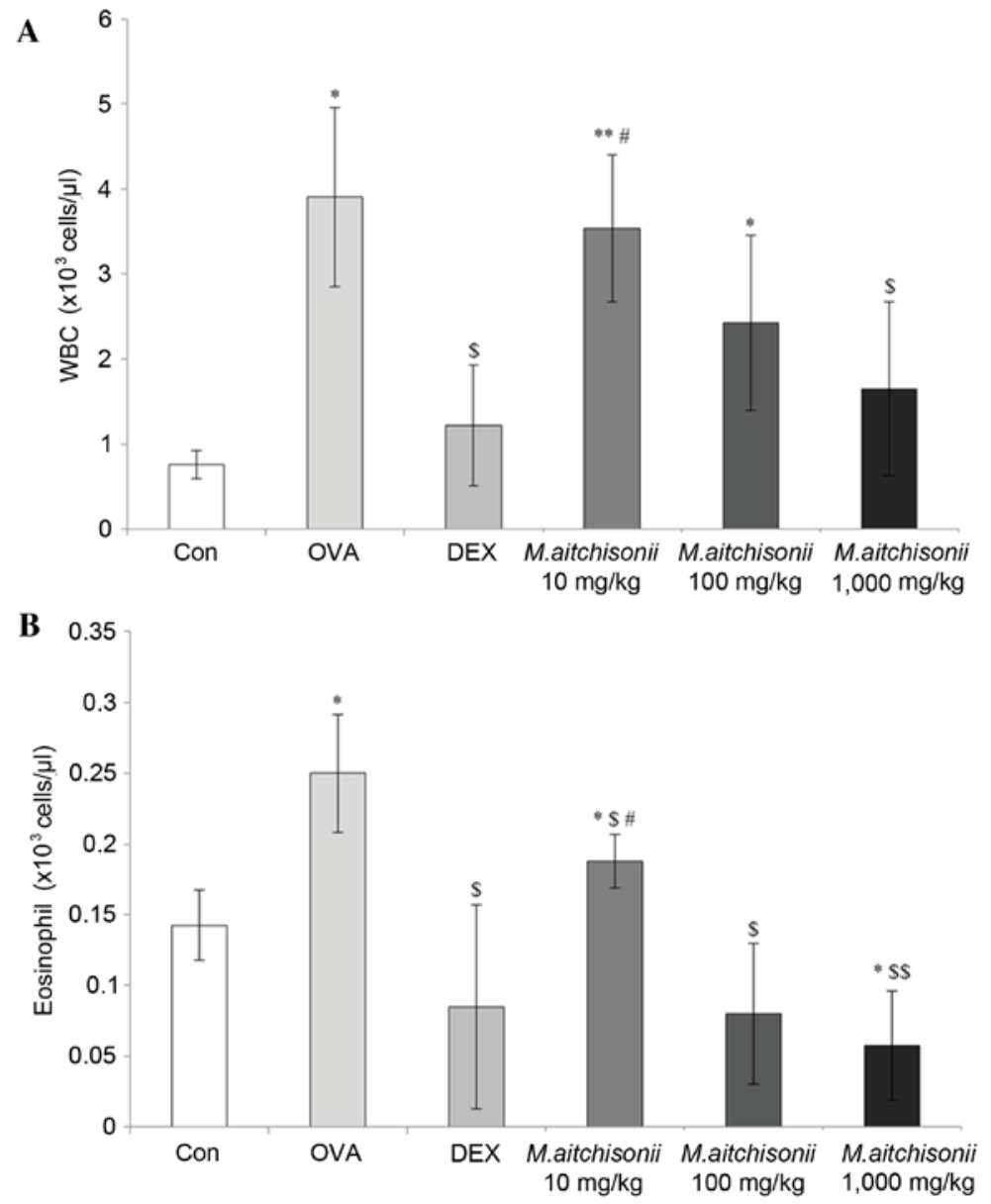

Figure 1. M. atichisonii suppressed the OVA-induced increase of WBC and eosinophil levels. (A) M. atichisonii dose-dependently suppressed the number of WBCs. (B) Treatment with 100 to $1,000 \mathrm{mg} / \mathrm{kg} \mathrm{M}$. atichisonii significantly decreased the level of eosinophils similarly to treatment with DEX. Each bar represents the mean \pm standard deviation $(\mathrm{n}=6)$. ${ }^{\mathrm{P}} \mathrm{P}<0.05$ vs. Con; ${ }^{*} \mathrm{P}<0.001$ vs. Con; ${ }^{\mathrm{S}} \mathrm{P}<0.05$ vs. OVA-induced asthma, ${ }^{\mathrm{s}} \mathrm{P}<0.001$ vs. OVA-induced asthma; ${ }^{\text {"P}} \mathrm{P}<0.05$ vs. DEX treatment. WBC, white blood cell; Con, control; OVA, ovalbumin; Dex, dexamethasone.

group, M. atichisonii dramatically increased WBC count, when compared with the level of WBCs in the control group. However, in the DEX treated group, WBC number decreased by a similar amount in the control group (Fig. $1 \mathrm{~A} ; \mathrm{P}<0.05$ or $\mathrm{P}<0.01)$. M. atichisonii suppressed WBC proliferation induced by OVA in a dose-dependent manner. The number of WBCs in the $1,000 \mathrm{mg} / \mathrm{kg}$ M. atichisonii treatment group was similar to that in the DEX treatment.

Eosinophil number was dramatically was more affected by M. atichisonii treatment than WBC number (Fig. 1B; $\mathrm{P}<0.05$ or $\mathrm{P}<0.01)$. M. atichisonii dose-dependently suppressed eosinophil proliferation and the levels of eosinophils in the $1,000 \mathrm{mg} / \mathrm{kg} /$ day M. atichisonii treatment group, and this was similar to that in DEX treatment.

M. atichisonii effectively decreased the quantity of $\operatorname{IgE}$ in the BALF of OVA-induced asthma mice. IgE is related to the hyperresponsiveness of asthma and serves an important role in asthma occurrence (28). M. atichisonii effectively decreased the level of $\operatorname{IgE}$ in a dose-dependent manner, which was increased by OVA treatment, when compared with that the in OVA treatment group $(8.2 \pm 0.69 \mathrm{ng} / \mathrm{ml})$. In addition, the quantity of $\mathrm{IgE}$ in the $1,000 \mathrm{mg} / \mathrm{kg}$ treatment group $(2.7 \pm 1.02 \mathrm{ng} / \mathrm{ml})$ was similar to that in the DEX treatment group $(2.4 \pm 0.54 \mathrm{ng} / \mathrm{ml}$; Fig. 2 ; $\mathrm{P}<0.05$ or $\mathrm{P}<0.01)$.

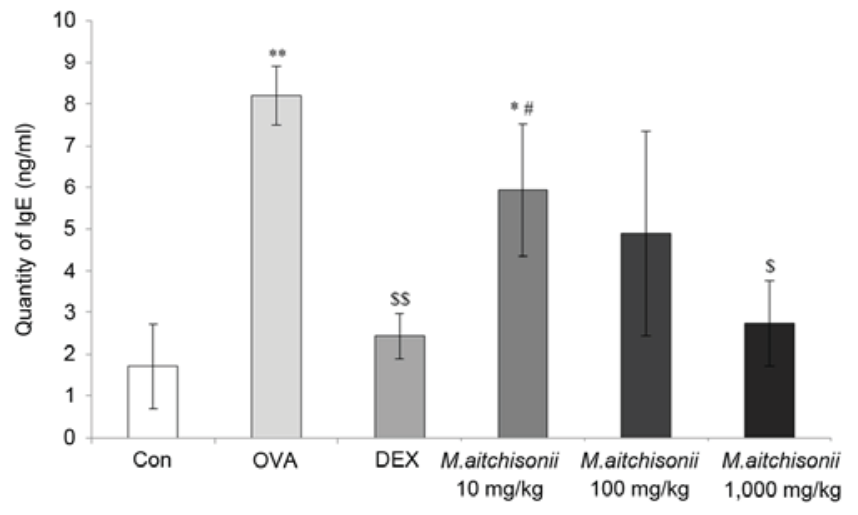

Figure 2. M. atichisonii decreased the quantity of $\operatorname{IgE}$ in bronchoalveolar lavage fluid in OVA-induced asthma animals in a dose-dependent manner. Each bar represents the mean \pm standard deviation $(n=6)$. ${ }^{*} \mathrm{P}<0.05$ vs Con; ${ }^{* *} \mathrm{P}<0.001$ vs. Con; ${ }^{\$} \mathrm{P}<0.05$ vs. OVA-induced asthma, ${ }^{\$ \$} \mathrm{P}<0.001$ vs. OVA-induced asthma; ${ }^{\#} \mathrm{P}<0.05$ vs. DEX treatment. IgE, immunoglobulin E; Con, control; OVA, ovalbumin; Dex, dexamethasone.

Mycoleptodonoides atichisonii recovered the typical asthmatic morphological changes in the lung. To analyze the morphological changes in the lung that were induced by OVA treatment, hematoxylin and eosin staining was used, in 


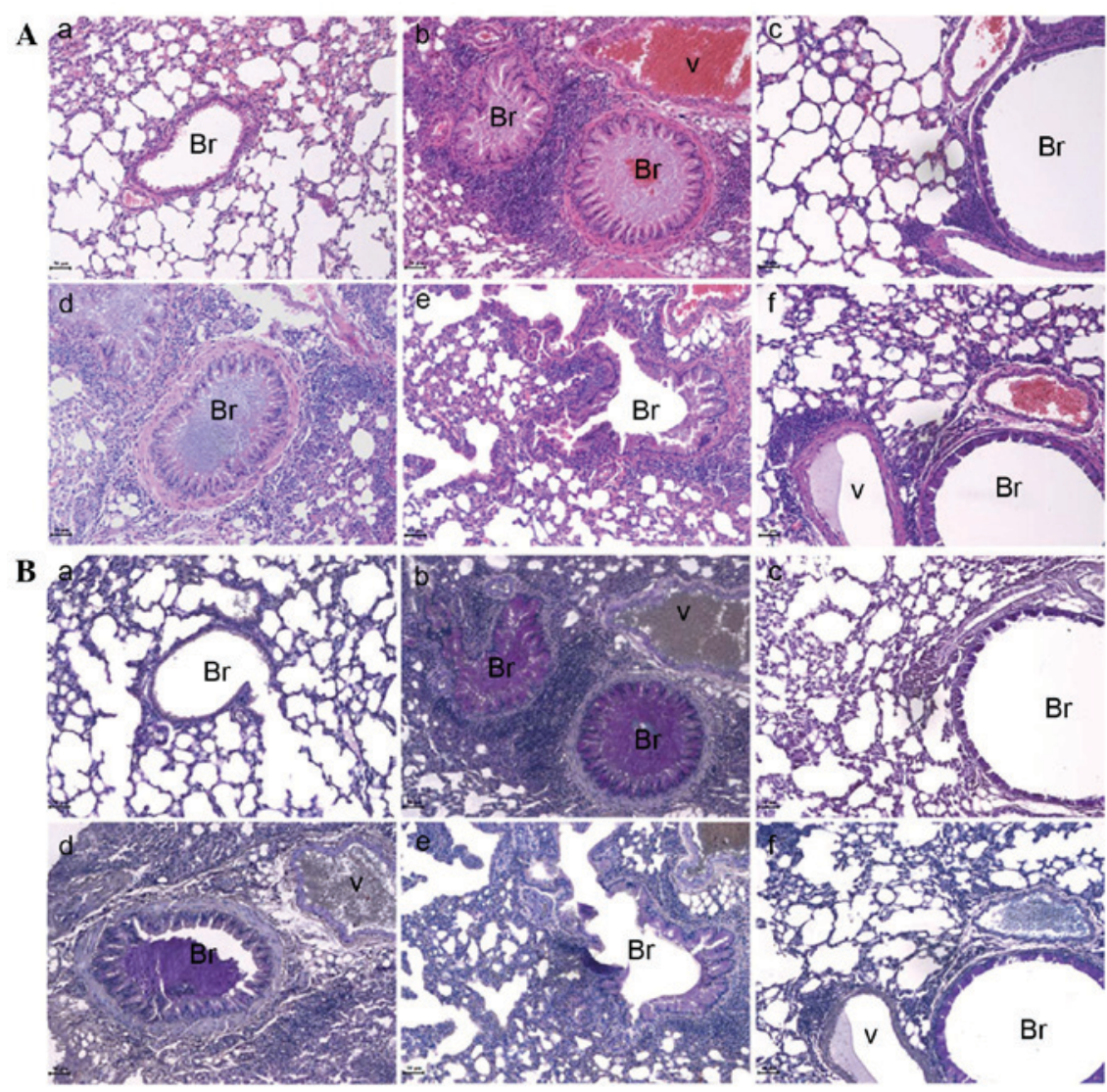

Figure 3. M. atichisonii recovered the asthmatic changes in the lung. (A) $M$. atichisonii effectively and dose-dependently recovered the ovalbumin-induced morphological changes such as mucous secretion in bronchioles, epithelial hyperplasia and eosinophil infiltration. This is a representative image of a lung stained by hematoxylin and eosin. (B) M. atichisonii decreased ovalbumin-induced mucous secretion similar to dexamethasone. This is a representative image of a lung stained by Periodic Acid-Schiff. Scale bar (bottom-left of each image)=50 $\mu \mathrm{m}$. a, control; b, ovalbumin; c, dexamethasone; d, $10 \mathrm{mg} / \mathrm{kg} / \mathrm{day}$ M. atichisonii; e, $100 \mathrm{mg} / \mathrm{kg} /$ day M. atichisonii; f, $1,000 \mathrm{mg} / \mathrm{kg} / \mathrm{day}$ M. atichisonii. Br, bronchiole; V, vessel.

addition to PAS staining (Fig. 3). In the lungs of mice with OVA-induced asthma, typical histopathological changes were observed such as airway remodeling, mucous hyper-secretion, epithelial hyperplasia and eosinophil infiltration (Fig. 3A-b). In particular, PAS stained mucous hyper-secretion in the bronchioles was clearly observed using the specific staining method (Fig. 3B-b). DEX, which is typically used as a representative anti-asthmatic drug, significantly suppressed the morphological changes in the lung (Fig. 3A-c) and completely prevented mucous secretion (Fig. 3B-c). M. atichisonii not only recovered the asthmatic alterations (Fig. 3A-d-f) but also suppressed mucous secretion (Fig. 3B-d-f). These results suggested that $M$. atichisonii may ameliorate airway obstruction.

Mycoleptodonoides atichisonii downregulated the expressions of MHC class II molecules and T cells. In the $100 \mathrm{mg} / \mathrm{kg} /$ day M.atichisonii treatment and $1,000 \mathrm{mg} / \mathrm{kg} / \mathrm{day}$ M. atichisonii treatment, expression of CD3+ total $\mathrm{T}$ cell (Fig. 4A; $\mathrm{P}<0.05$ or $\mathrm{P}<0.01$ ) was almost fully diminished. The expression of CD4+ helper $\mathrm{T}$ cells was suppressed in a dose-dependent manner (Fig. 4B; $\mathrm{P}<0.05$ or $\mathrm{P}<0.01$ ). A total of $1,000 \mathrm{mg} / \mathrm{kg} /$ day $M$. atichisonii treatment effectively inhibited the expression of CD4+ helper T cells (Fig. 4B-f; $\mathrm{P}<0.05$ or $\mathrm{P}<0.01)$ when compared with the DEX treatment group (Fig. 4B-c; $\mathrm{P}<0.05$ or $\mathrm{P}<0.01$ ). In the $100 \mathrm{mg} / \mathrm{kg} / \mathrm{day}$ or more $M$. atichisonii treatment group, the expression pattern of CD8+ cytotoxic T cells (Fig. 4C; $\mathrm{P}<0.05$ or $\mathrm{P}<0.01$ ) was the same as that observed for the CD4+ helper T cells, which was that they were almost fully diminished. Although M. atichisonii downregulated the expression of CD19+ B cells, the decreased level of CD19+ B cells was lower compared with other groups including CD3+ total T cell, CD4+ helper T cell, and CD8+ cytotoxic T cell (Fig. 4D; $\mathrm{P}<0.05$ or $\mathrm{P}<0.01$ ). The expression of MHC class II+ molecule (Fig. $4 \mathrm{E} ; \mathrm{P}<0.05$ or $\mathrm{P}<0.01)$ almost disappeared in the $100 \mathrm{mg} / \mathrm{kg} / \mathrm{day}$ M. atichisonii treatment and in the $1,000 \mathrm{mg} / \mathrm{kg} / \mathrm{day}$ M. atichisonii treatment groups. The $1,000 \mathrm{mg} / \mathrm{kg} /$ day $M$. atichisonii treatment effectively inhibited the expression of MHC class II+ molecules (Fig. 4E-f; $\mathrm{P}<0.05$ or $\mathrm{P}<0.01$ ) more, when compared with the DEX treatment group (Fig. 4E-c; $\mathrm{P}<0.05$ or $\mathrm{P}<0.01)$.

Although $M$. atichisonii appears to control levels of both T cells (CD3+, CD4+, CD8+) and B cells (CD19+), the potency to modulate $\mathrm{B}$ cell (CD19+) proliferation may be smaller than that of $\mathrm{T}$ cell $(\mathrm{CD} 3+, \mathrm{CD} 4+, \mathrm{CD} 8+)$ proliferation, however it downregulated CD3+ positive cells (total T cell) and CD8+ positive cells (cytotoxic $\mathrm{T}$ cell) and dose-dependently regulated CD4+ positive cell (helper T cell).

M. atichisonii controlled T-bet and GATA-3. In order to compare the suppressive effects of the Th1 cell transcription 

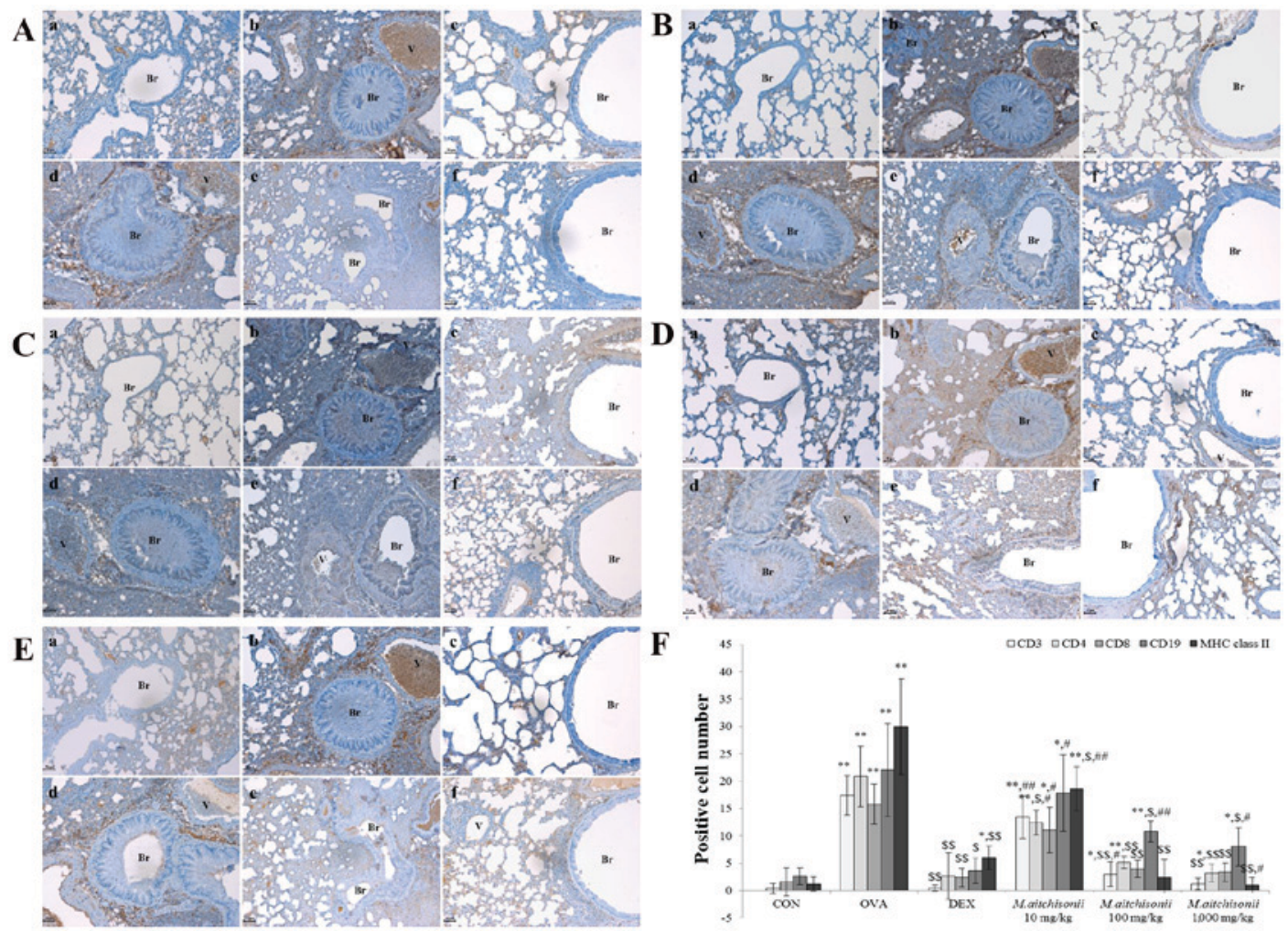

Figure 4. M. atichisonii almost completely inhibited the expressions of several cells related to asthma occurrence. (A) M. atichisonii completely inhibited the expression of CD3+ cell levels. (B) M. atichisonii dose-dependently suppressed CD4+ cells. (C) M. atichisonii almost fully diminished CD8+ cell levels. (D) M. atichisonii downregulated the expression of the CD19+ cell, although the effect of $M$. atichisonii was smaller than CD3+, CD+8 and MHC class II. (E) The effect of 100 or $1,000 \mathrm{mg} / \mathrm{kg}$ M. atichisonii treatment against MHC class II was greater than that of DEX treatment. (F) Quantification of expression. Each bar represents the mean \pm standard deviation ( $\mathrm{n}=6$ ). a, Con; b, OVA; c, DEX; d, $10 \mathrm{mg} / \mathrm{kg} / \mathrm{day}$ M. atichisonii; e, $100 \mathrm{mg} / \mathrm{kg} / \mathrm{day}$ M. atichisonii; f, $1,000 \mathrm{mg} / \mathrm{kg} /$ day M. atichisonii. ${ }^{*} \mathrm{P}<0.05$ vs. control; ${ }^{* *} \mathrm{P}<0.001$ vs. Con; ${ }^{\$} \mathrm{P}<0.05$ vs. OVA-induced asthma, ${ }^{\$ \$} \mathrm{P}<0.001$ vs. OVA-induced asthma; ${ }^{\prime \prime} \mathrm{P}<0.05$ vs. DEX treatment, ${ }^{\# \#} \mathrm{P}<0.01$ vs. DEX treatment. Br, bronchiole; V, vessel; MHC, major histocompatibility complex; Con, control; OVA, ovalbumin; DEX, dexamethasone.
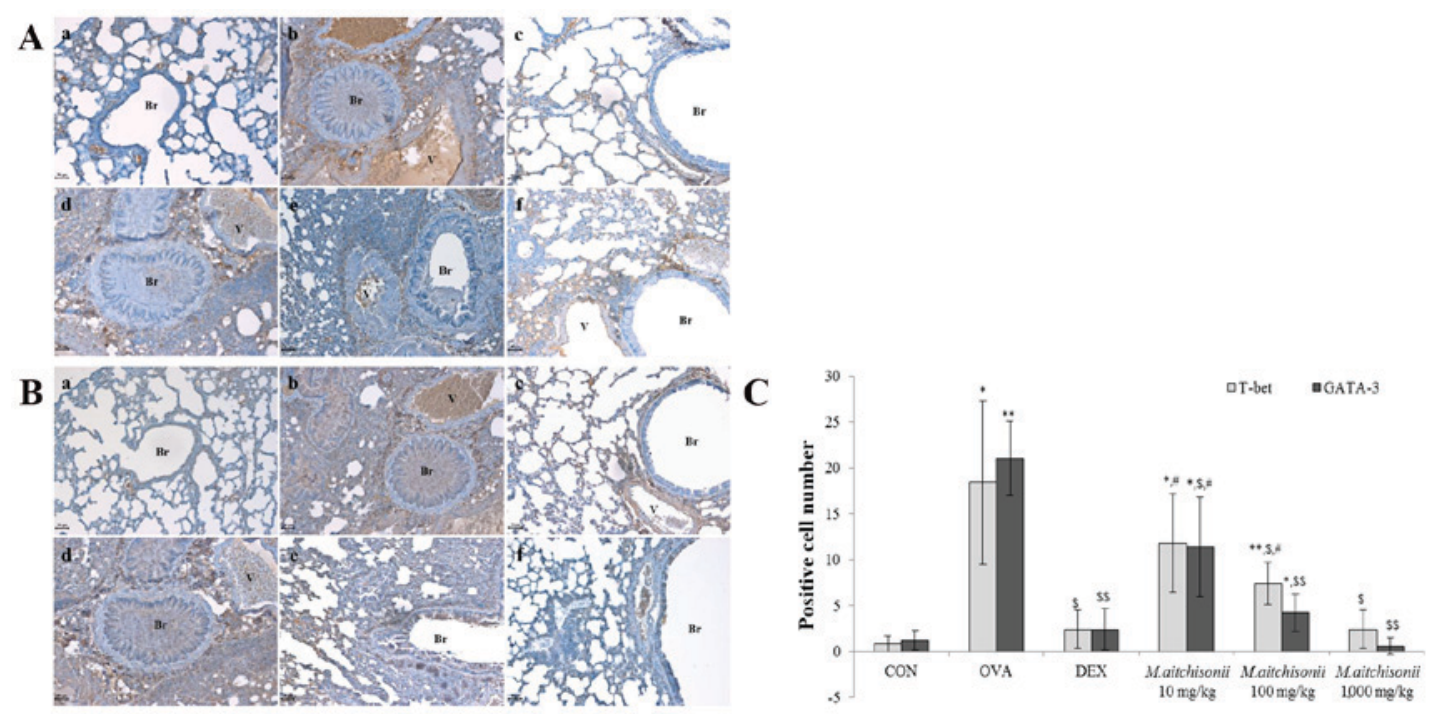

Figure 5. M. atichisonii controlled T-bet and GATA-3 expression levels. (A) M. atichisonii dose-dependently suppressed the expression of T-bet. (B) M. atichisonii downregulated GATA-3 more than T-bet, and the effect of M. atichisonii was similar the effect of dexamethasone. (C) Quantification of expression Each bar represents the mean \pm standard deviation ( $\mathrm{n}=6$ ). a, Con; b, OVA; c, DEX; d, $10 \mathrm{mg} / \mathrm{kg} / \mathrm{day}$ M. atichisonii; e, $100 \mathrm{mg} / \mathrm{kg} / \mathrm{day} \mathrm{M.} \mathrm{atichisonii;} \mathrm{f}$, $1,000 \mathrm{mg} / \mathrm{kg} /$ day M. atichisonii. ${ }^{*} \mathrm{P}<0.05$ vs. Con; ${ }^{* *} \mathrm{P}<0.001$ vs. Con; ${ }^{\$} \mathrm{P}<0.05$ vs. OVA-induced asthma, ${ }^{\$ \$} \mathrm{P}<0.001$ vs. OVA-induced asthma; ${ }^{\sharp} \mathrm{P}<0.05$ vs. DEX. $\mathrm{Br}$, bronchiole; V, vessel; Con, control; OVA, ovalbumin; DEX, dexamethasone.

factor, T-bet, and the Th2 cell transcription factor, GATA-3, the changes of expressions on T-bet and GATA-3 were measured via immunohistochemical staining (Fig. 5). The expressions of T-bet and GATA-3 in the OVA treatment 

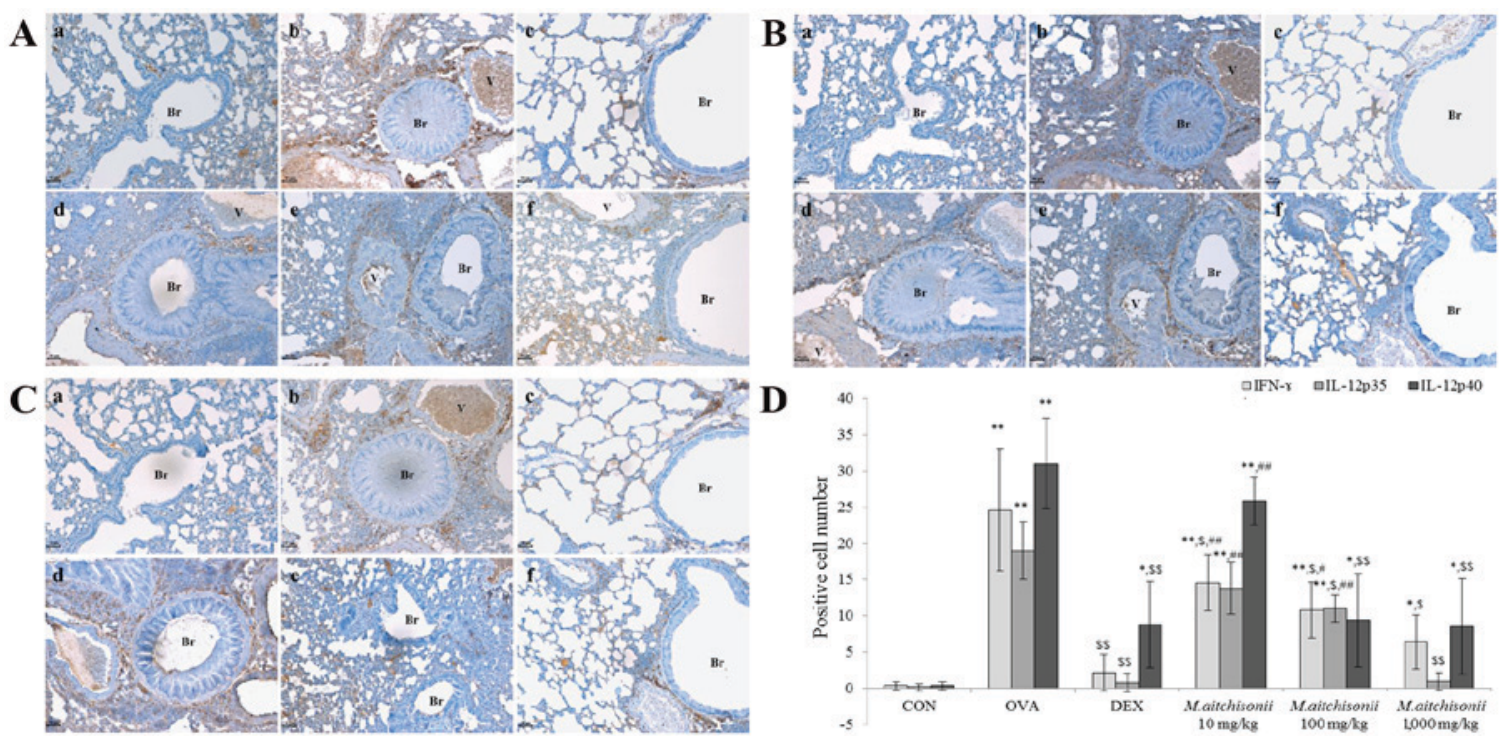

Figure 6. M. atichisonii suppressed the expressions of IFN- $\gamma$ and IL-12p35. (A) In a dose-dependent manner, M. atichisonii suppressed the expression of IFN- $\gamma$, however, the effect of M. atichisonii is smaller than the effect of DEX. (B) Although M. atichisonii inhibited the expression of IL-12p35, the effect of $M$. atichisonii in $10 \mathrm{mg} / \mathrm{kg}$ treatment and $100 \mathrm{mg} / \mathrm{kg}$ treatment groups was small. The $1,000 \mathrm{mg} / \mathrm{kg}$ M. atichisonii treatment suppressed the expression of IL12-p35 similarly to DEX treatment. (C) IL-12p40 may be affected by DEX and M. atichisonii as the changes of expression level were not large following treatment. (D) Quantification of expression. Each bar represents the mean \pm standard deviation (n=6). a, Con; b, OVA; c, DEX; d, 10 mg/kg/day M. atichisonii; e, $100 \mathrm{mg} / \mathrm{kg} /$ day M. atichisonii; $\mathrm{f}, 1,000 \mathrm{mg} / \mathrm{kg} /$ day M. atichisonii. ${ }^{*} \mathrm{P}<0.05$ vs. Con; ${ }^{* *} \mathrm{P}<0.001$ vs. Con; ${ }^{\$} \mathrm{P}<0.05$ vs. OVA-induced asthma, ${ }^{\$ \$} \mathrm{P}<0.001$ vs OVA-induced asthma; ${ }^{~} \mathrm{P}<0.05$ vs. DEX treatment, ${ }^{\# /} \mathrm{P}<0.01$ vs. DEX treatment. Br, bronchiole; V, vessel; IFN- $\gamma$; interferon- $\gamma$; IL, interleukin; Con, control; OVA, ovalbumin; DEX, dexamethasone.

group was significantly increased, when compared with the control, however DEX decreased the expressions of T-bet and GATA-3, which was induced by OVA, to a similar level as the control groups (Fig. 5A and B). Although M. atichisonii dose-dependently downregulated the expression of T-bet, there was no significant difference between $100 \mathrm{mg} / \mathrm{kg}$ M. atichisonii treatment and $1,000 \mathrm{mg} / \mathrm{kg}$ M. atichisonii treatment (Fig. $5 \mathrm{C} ; \mathrm{P}<0.05$ or $\mathrm{P}<0.01$ ). Conversely, from treatment with $10 \mathrm{mg} / \mathrm{kg} \mathrm{M}$. atichisonii to $1,000 \mathrm{mg} / \mathrm{kg}$, the changes in GATA-3 expression were dependent on the dose-response relationship (Fig. 5C; $\mathrm{P}<0.05$ or $\mathrm{P}<0.01$ ).

M. atichisonii suppressed the expression of Th1-related cytokines. M. atichisonii dose-dependently suppressed the expression of IFN- $\gamma$ and the effect of $M$. atichisonii on INF- $\gamma$ was less than DEX (Fig. 6A). The results of IFN- $\gamma$ by M. atichisonii were similar to that of T-bet (Fig. 5A). M. atichisonii inhibited the expression of IL-12p35 (Fig. 6B). The effect of $1,000 \mathrm{mg} / \mathrm{kg} M$. atichisonii treatment on IL-12p40 was similar to that of dexamethasone. DEX and $M$. atichisonii effectively suppressed the expression of IL-12p40 (Fig. 6C). Although there was no significant difference between $10 \mathrm{mg} / \mathrm{kg}$ M. atichisonii treatment and $100 \mathrm{mg} / \mathrm{kg}$ M. atichisonii treatment $(\mathrm{P}>0.05)$, in the $1,000 \mathrm{mg} / \mathrm{kg} \mathrm{M}$. atichisonii treatment group, IL-12p35 levels were almost fully diminished (Fig. 6D).

M. atichisonii almost fully inhibited the expression of Th2-related cytokines such as $I L-5, I L-6$, and IL-13. In order to measure the downregulation effect of $M$. atichisonii on Th2-related cytokines, such as TNF- $\alpha$ (Fig. 7A), IL-4 (Fig.7B), IL-5 (Fig. 7C), IL-6 (Fig. 7D) and IL-13 (Fig 7E), immunohistochemical analysis was conducted. Although M. atichisonii did not completely prevent the expression of TNF- $\alpha$, it was similar to that of DEX (Fig. 7A). M. atichisonii dose-dependently suppressed the expression of IL-4, but the suppression was less than DEX (Fig. 7B and F). The expression of IL-5 was controlled by M. atichisonii and the effect was similar to DEX. In particular, IL-6 and IL-13 were dose-dependently suppressed by $M$. atichisonii treatment more than by DEX (Fig. 7F).

Nicotinic acid (niacin), oleic acid and linoleic acid may act as anti-asthmatic compounds in M. aitchisonii. To identify the compounds in $M$. aitchisonii that may possess anti-asthmatic properties, GC-MS analysis was conducted. Not all compounds in M. aitchisonii were isolated, however nicotinic acid (niacin), oleic acid and linoleic acid were identified as candidate compounds. Fig. 8 presents the identification of silylated fatty acids. Of the identified fatty acids, niacin, linoleic acid and linoleic acid were analyzed at retention times of 18.21, 28.01 and 28.06 min respectively.

\section{Discussion}

Eosinophils are a key mediator of innate and adaptive immunity $(29,30)$. The differentiation and activation of eosinophils is strongly related to the IL-5 gene; if the $I L-5$ gene is depleted, airway eosinophilia cannot occur (31). Eosinophils are increased in number in asthma, and this is induced by IL-5 (11). In allergic situations, eosinophils remain for 8-12 h in circulatory blood, and for an additional 8-12 days in tissue following the removal of the stimuli (32). In the present study, although the expression of IL-5 was more suppressed by M. atichisonii 

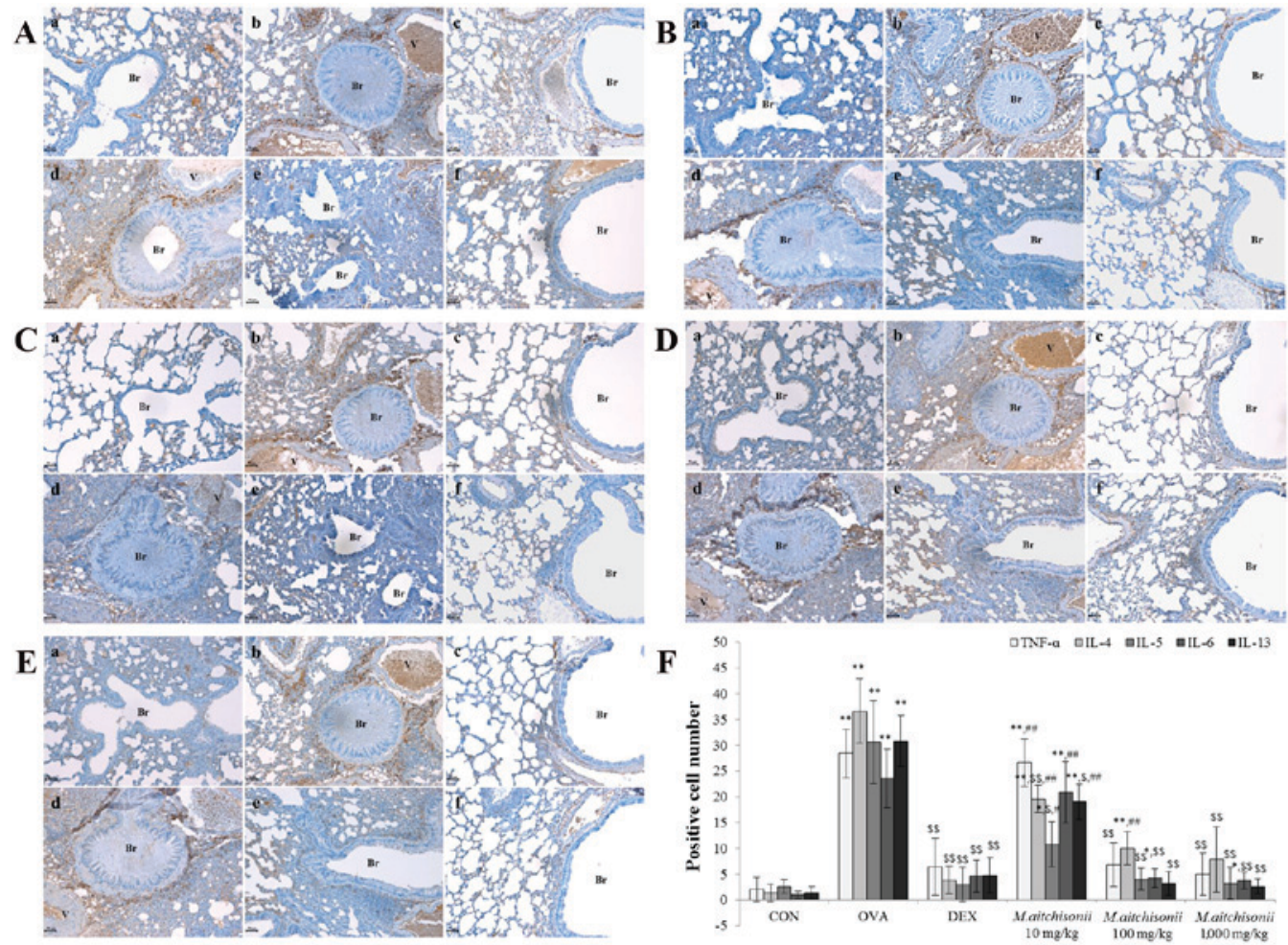

Figure 7. M. atichisonii significantly inhibited the expression of Th2-related cytokines in a dose-dependent manner. (A) M. atichisonii suppressed the expression of TNF- $\alpha$ similarly to dexamethasone treatment. (B) M. atichisonii downregulated the expression of IL-4. (C) M. atichisonii significantly inhibited the expression of IL-5, similar to treatment with dexamethasone. (D) M. atichisonii dramatically inhibited the expression of IL-6 more than treatment with dexamethasone. (E) The expression of IL-13 dramatically inhibited the expression of IL-6 more than treatment with dexamethasone. (F) Quantification of expression. Each bar represents the mean \pm standard deviation (n=6). a, Con; b, OVA; c, DEX; d, $10 \mathrm{mg} / \mathrm{kg} / \mathrm{day}$ M. atichisonii; e, $100 \mathrm{mg} / \mathrm{kg} / \mathrm{day}$ M. atichisonii; f, $1,000 \mathrm{mg} / \mathrm{kg} /$ day M. atichisonii. ${ }^{*} \mathrm{P}<0.05$ vs. control; ${ }^{* *} \mathrm{P}<0.001$ vs. control; ${ }^{\$} \mathrm{P}<0.05$ vs. OVA-induced asthma, ${ }^{\$}{ }^{\$} \mathrm{P}<0.001$ vs. OVA-induced asthma; ${ }^{*} \mathrm{P}<0.05$ vs. DEX treatment, ${ }^{\# \#<0.01 ~ v s . ~ D E X ~ t r e a t m e n t . ~ T h, ~ T ~ h e l p e r ; ~ T N F-~} \alpha$, tumor necrosis factor- $\alpha$; IL, interleukin; Br, bronchiole; V, vessel; Con, control; OVA, ovalbumin; DEX, dexamethasone.

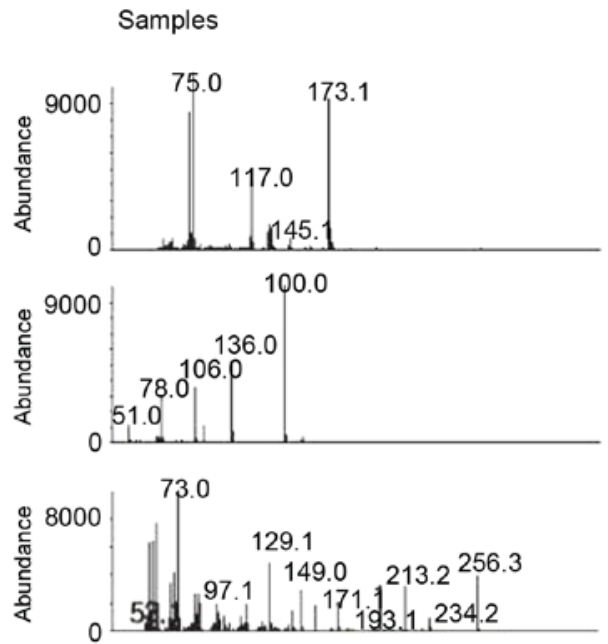

NIST Lib.
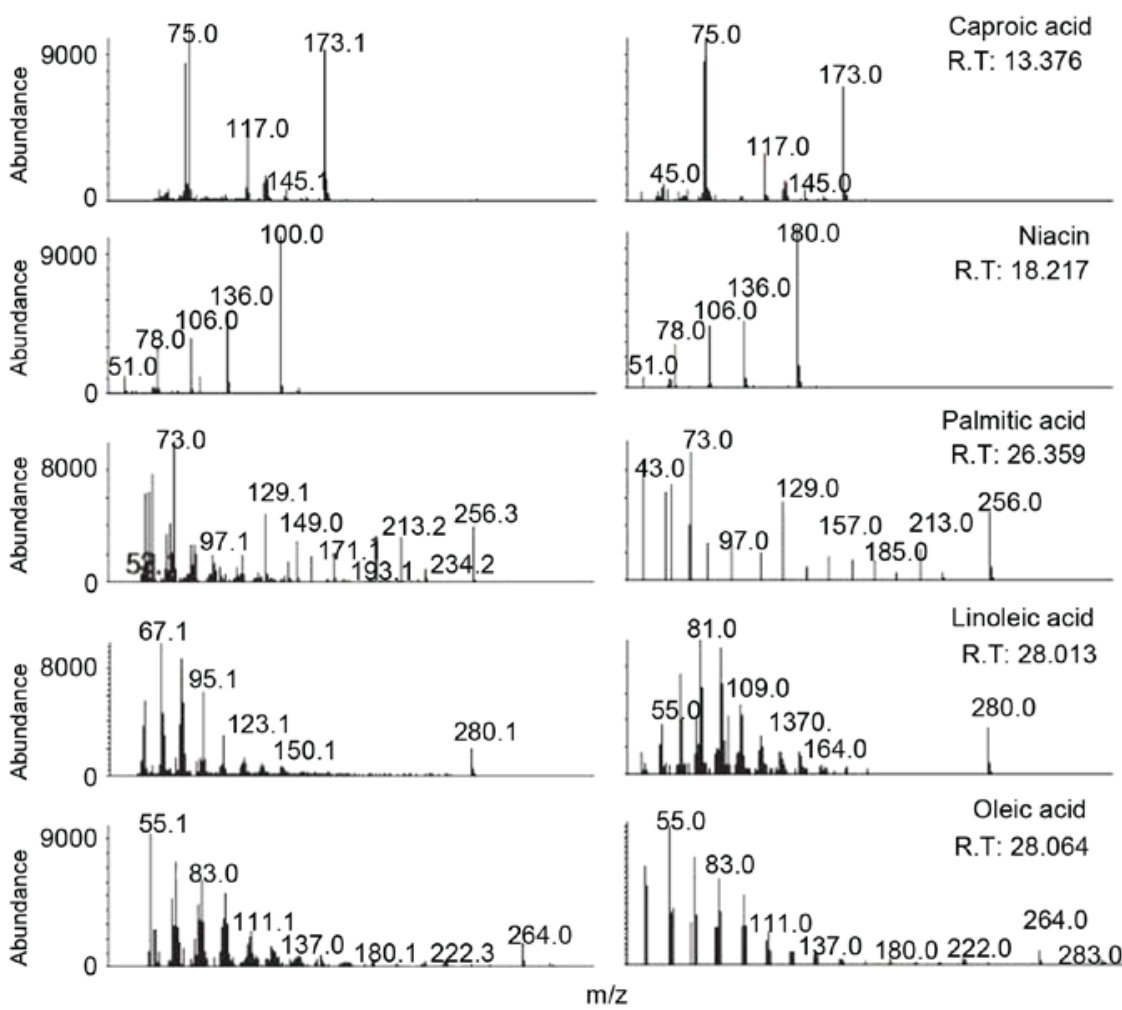

Figure 8. Gas chromatography/mass spectrometry analysis of M. atichisonii. 
than that of eosinophils, the downregulatory patterns were similar for both, indicating that $M$. atichisonii may suppress eosinophils through IL-5. As the level of IL-5 suppression by M. atichisonii was larger than the other effects, IL-5 might be one of the key mediators in the preventive mechanism of M. atichisonii against asthma.

MHC class II molecules, which are made by antigen presenting cells, have the function of presenting processed antigens to helper $\mathrm{T}$ cells and triggering acquired immunity (33). MHC class II+ expression was almost completely eliminated by $100 \mathrm{mg} / \mathrm{kg}$ M. atichisonii treatment, confirming that $M$. atichisonii may completely control MHC class II molecule expression, which serves an important role in asthma occurrence.

Based on the changes in IFN- $\gamma$ levels, a controversial hypothesis regarding the mechanism underlying asthma was previously proposed that implicated the Th1/Th2 cell imbalance and $\mathrm{T}$ cell priming induced by allergens (34). $M$. atichisonii slightly decreased not only the expressions of Th2-related factors, but also that of IFN- $\gamma$ increased by OVA (Fig. 4D) in the present study and this result may support the $\mathrm{T}$ cell priming theory. IL-12 is produced by cells including dendritic cells, macrophages and monocytes (35) and is considered an IFN- $\gamma$-inducing factor because it stimulates the production of IgM and IFN- $\gamma$ (8). Although M. atichisonii suppresses or inhibits most asthma-induced factors, the key factors for the anti-asthmatic effect may be IL-5, IL-6 and IL-13 (Fig 7C-E). The ratio of Th17 cells and Treg cells is related to the late phase asthma induction and, in the case of late phase asthma, the analysis of Th17 cells and Treg cells may be important (36).

In the current study, the authors determined that M. atichisonii lowered the OVA-induced level of WBCs and eosinophils in BALF and the level of $\mathrm{IgE}$ in serum, recovered respiratory changes, such as mucous secretion, epithelial cell hyperplasia and eosinophil infiltration and finally ameliorated airway obstruction. This was controlled by $\mathrm{T}$ cell-related molecules, such as CD3+, CD4+ and CD8+, as well as by MHC class II+ molecules that were increased following OVA treatment. Ultimately, this led to downregulated T-bet and GATA-3 levels, and a dose-dependent decreased to the level of Th1-related cytokines, IFN- $\gamma$ and IL-12p40, and Th2-related cytokines, TNF- $\alpha$, IL-4, IL-5, IL-6 and IL-13. In particular, the expression of IL-5, IL- 6 and IL-13 increased by OVA treatment were almost completely eliminated by M. atichisonii application.

In this study, niacin, oleic acid and linoleic acid in $M$. aitchisonii were identified and isolated. Melton (37) previously reported that nicotinic acid reduced the frequency of asthmatic paroxysm. In addition, oleic acid has beneficial effects in inflammatory related diseases (38) and linoleic acid is one of the mediators that regulate inflammations and asthma (39).

The present study is one of the ongoing efforts to identify appropriate anti-asthmatic drug candidates. From the results, it may be concluded that $M$. atichisonii has an anti-asthmatic effect and that the pharmacological effect may be based on the suppression or inhibition of various factors related to Th1 and Th2. In particular, IL-5, IL-6 and IL-13 may be some of the most important factors related to asthma occurrence, and they are modulated by M. atichisonii. M. atichisonii is a promising drug that is believe to be key in the control of asthma.

\section{Acknowledgements}

The current study was conducted with a fund from the Korea Forest Service (grant no. S121313L090100).

\section{References}

1. World Health Organization: Asthma Fact Sheet No 307, November, 2013.

2. United States Environmental Protection Agency (EPA): Asthma Facts EPA-402-F-04-019, March, 2013.

3. Kay AB: Allergy and allergic diseases. First of two parts. N Engl J Med 344: 30-37, 2001

4. National Asthma Education and Prevention Program: National asthma education and prevention program. Expert panel report: Guidelines for the diagnosis and management of asthma update on selected topics-2002. J Allergy Clin Immunol 110 (5 Suppl): S141-S219, 2002.

5. Lazarevic V and Glimcher LH: T-bet in disease. Nature Immunol 12: 597-606, 2011.

6. Zhu J, Jankovic D, Oler AJ, Wei G, Sharma S, Hu G, Guo L, Yagi R, Yamane H, Punkosdy G, et al: The transcription factor T-bet is induced by multiple pathways and prevents an endogenous $\mathrm{T}$ helper-2 program during $\mathrm{T}$ helper-1 responses. Immunity 37: 660-673, 2012.

7. Zedan MM, El-Chennawi FA and Fouda AE: Interleukin-12 and peripheral blood invariant natural killer T cells as an axis in childhood asthma pathogenesis. Iran J Allergy Asthma Immunol 9: 43-48, 2010.

8. Trinchieri G: Interleukin-12: A cytokine at the interface of inflammation and immunity. Adv Immunol 70: 83-243, 1998.

9. Hamza T, Barnett JB and Li B: Interleukin 12 a key immunoregulatory cytokine in infection applications. Int J Mol Sci 11: 789-806, 2010

10. Yagi R, Zhu J and Paul WE: An updated view on transcription factor GATA3-mediated regulation of Th1 and Th2 cell differentiation. Int Immunol 23: 415-420, 2011.

11. Uhm TG, Kim BS and Chung IY: Eosinophil development, regulation of eosinophil-specific genes and role of eosinophils in the pathogenesis of asthma. Allergy Asthma Immunol Res 4: 68-79, 2012.

12. Platts-Mills TA: The role of immunoglobulin $\mathrm{E}$ in allergy and asthma. Am J Respir Crit Care Med 164: S1-S5, 2001.

13. Kamimura D, Ishihara K and Hirano T: IL-6 signal transduction and its physiological roles: The signal orchestration model. Rev Physiol Biochem Pharmacol 149: 1-38, 2003.

14. Neveu WA, Allard JL, Raymond DM, Bourassa LM, Burns SM, Bunn JY, Irvin CG, Kaminsky DA and Rincon M: Elevation of IL-6 in the allergic asthmatic airway is independent of inflammation but associates with loss of central airway function. Respir Res 11: 28, 2010

15. Berry M, Brightling C, Pavord I and Wardlaw A: TNF-alpha in asthma. Curr Opin Pharmacol 7: 279-282, 2007.

16. Lukacs NW, Strieter RM, Chensue SW, Widmer M and Kunkel SL: TNF-alpha mediates recruitment of neutrophils and eosinophils during airway inflammation. J Immunol 154: 5411-5417, 1995

17. Scheurich $\mathrm{P}$, Thoma B, Ucer $U$ and Pfizenmaier $K$ : Immunoregulatory activity of recombinant human tumor necrosis factor (TNF)-alpha: Induction of TNF receptors on human T cells and TNF-alpha-mediated enhancement of T cell responses. J Immunol 138: 1786-1790, 1987.

18. Bosnjak B, Stelzmueller B, Erb KJ and Epstein MM: Treatment of allergic asthma: Modulation of Th2 cells and their responses. Respir Res 12: 114, 2011.

19. Barnes PJ: Current issues for establishing inhaled corticosteroids as the anti-inflammatory agents of choice in asthma. J Allergy Clin Immunol 101: S427-S433, 1998.

20. Wise J: Corticosteroids for asthma may suppress growth in children in first year of treatment, researchers say. BMJ 349: g4623, 2014. 
21. Ciriaco M, Ventrice P, Russo G, Scicchitano M, Mazzitello G Scicchitano F and Russo E: Corticosteroid-related central nervous system side effects. J Pharmacol Pharmacother 4 (Suppl 1): S94-S98, 2013

22. Seo JW, Cho SC, Park SJ, Lee EJ, Lee JH, Han SS, Pyo BS, Park DH and Kim BH: 1'-Acetoxychavicol acetate isolated from Alpinia galangal ameliorates ovalbumin-induced asthma in mice. PLoS One 8: e56447, 2013.

23. Bang MA, Seo JH, Seo JW, Jo GH, Jung SK, Yu R, Park DH and Park SJ: Bacillus subtilis KCTC 11782BP-produced alginate oligosaccharide effectively suppresses asthma via T-helper cell type 2-related cytokines. PLoS One 10: e0117524, 2015.

24. Chandrasekaran G, Oh DS and Shin HJ: Versatile applications of the culinary-medicinal mushroom Mycoeptodonoides aitchisonii (Berk.) Maas G. (Higher Basidiomycetes): A review. Int J Med Mushrooms 14: 395-401, 2012.

25. Okuyama S, Lam NV, Hatakeyama T, Terashima T, Yamagata K and Yokogoshi $\mathrm{H}$ : Mycoleptodonoides aitchisonii affects brain nerve growth factor concentration in newborn rats. Nutr Neurosci 7: 341-349, 2004.

26. Lee MR, Begum S, Oh DS, Wee AJ, Yun BS and Sung CK: Ameliorating effect of Mycoleptodonoides aitchisonii on high-fat diet-induced obese mice. Prev Nutr Food Sci 19: 69-74, 2014.

27. Choi JH, Suzuki T, Okumura H, Noguchi K, Kondo M, Nagai K, Hirai $\mathrm{H}$ and Kawagishi $\mathrm{H}$ : Endoplasmic reticulum stress suppressive compounds from the edible mushroom Mycoleptodonoides aitchisonii. J Nat Prod 77: 1729-1733, 2014.

28. Burrows B, Martinez FD, Halonen M, Barbee RA and Cline MG: Association of asthma with serum IgE levels and skin-test reactivity to allergens. N Engl J Med 320: 271-277, 1989.

29. Shamri R, Xenakis JJ and Spencer LA: Eosinophils in innate immunity: An evolving story. Cell Tissue Res 343: 57-83, 2011.

30. Galioto AM, Hess JA, Nolan TJ, Schad GA, Lee JJ and Abraham D: Role of eosinophils and neutrophils in innate and adaptive protective immunity to larval Strongyloides stercoralis in mice. Infect Immun 74: 5730-5738, 2006.
31. Kouro T and Takatsu K: IL-5- and eosinophil-mediated inflammation: From discovery to therapy. Int Immunol 21: 1303-1309, 2009.

32. Young B, Lowe JS, Stevens A, et al: Wheater's functional histology; a text and colour atlas. 5th edition. Edinburg, Elsevier, 2006.

33. Holling TM, Schooten E and van Den Elsen PJ: Function and regulation of MHC class II molecules in T-lymphocytes: Of mice and men. Human Immunol 65: 282-290, 2004.

34. Kim YK: Th1/Th2 imbalance vs. T cell priming in asthma. BioWave 7: SubNo.1, 2005.

35. Airoldi I, Guglielmino R, Carra G, Corcione A, Gerosa F, Taborelli G, Trinchieri G and Pistoia V: The interleukin-12 and interleukin-12 receptor system in normal and transformed human B lymphocytes. Haematologica 87: 434-442, 2002.

36. Singh A, Yamamoto M, Ruan J, Choi JY, Gauvreau GM, Olek S, Hoffmueller U, Carlsten C, FitzGerald JM, Boulet LP, et al: Th17/Treg ratio derived using DNA methylation analysis is associated with the late phase asthmatic response. Allergy Asthma Clin Immunol 10: 32, 2014.

37. Melton G: Treatment of Asthma by Nicotinic Acid. Br Med J 1: 600-601, 1943

38. Carrillo C, Cavia Mdel M and Alonso-Torre S: Role of oleic acid in immune system; mechanism of action; a review. Nutr Hosp 27: 978-990, 2012

39. Wendell SG, Baffi C and Holguin F: Fatty acids, inflammation, and asthma. J Allergy Clin Immunol 133: 1255-1264, 2014.

This work is licensed under a Creative Commons Attribution-NonCommercial-NoDerivatives 4.0 International (CC BY-NC-ND 4.0) License. 